\title{
Research and Practice of Entrepreneurship Education in "Tutor + Project + Team" Model in Colleges and Universities
}

\author{
Rui Li ${ }^{1, *}$, Pengzhong Dong ${ }^{1}$ \\ 1JiLin Engineering Normal University, Changchun, Jilin, China \\ *2238552865@qq.com
}

Keywords: Colleges and Universities Tutor; Project; Team Entrepreneurship Education

\begin{abstract}
The development of entrepreneurial education in colleges and universities is of great significance to the employment of high school students and the employment of college students. Should be based on the concept of team-based entrepreneurship education, adhere to the combination of entrepreneurship education and entrepreneurship, entrepreneurial team formation, entrepreneurial education system, simulation practice system and entrepreneurial combat system as the main structure, and actively explore how to build a team of entrepreneurial education model The On the basis of analyzing the entrepreneurial model of "mentor + project + team", this paper studies the ecological cultivation of higher education, which is of theoretical and practical significance for the construction of innovative college education system and the development of entrepreneurship education.

In the international context of information and globalization, innovation and development is a source of strength for national progress. In order to cultivate college students 'innovative consciousness and improve the development of students' personality, we need to cultivate the entrepreneurial spirit of college students. This has become the inevitable trend and important symbol of contemporary education development. However, due to the influence of traditional education mode and the influence of general self-regulated learning and innovation consciousness, the factors that affect the development of students 'ability of innovation and entrepreneurship are also multifaceted. Therefore, it is necessary to improve the development of college students' entrepreneurial team education system Particularly important.
\end{abstract}

\section{First, the Connotation of College Students Entrepreneurial Team}

College students entrepreneurial team refers to two or more students set up to engage in entrepreneurial activities for the common goal, with entrepreneurial spirit and entrepreneurial quality of students co-operation and management and shared responsibility groups. At present, the establishment of foreign entrepreneurial team and entrepreneurship education is better, mainly reflected in the students' ability to innovate better, pay attention to the invention and creation of students, at the same time, classroom teaching focus on student innovation awareness.

\section{Second, the Problems of College Entrepreneurship Team Training}

\section{Team Members Organizational Structure of a Single Cross-Professional Less}

In the existing practice of most college entrepreneurship education team, and more to the classbased students, and some focus on the balance of the grade structure, but the students participate in the multi-professional participation in the multi-professional, although this form of organization to ensure that the team Professional knowledge and ease of school management, but entrepreneurial activities alone is far from enough professional knowledge and skills. As the lack of entrepreneurial team and entrepreneurs are closely related to other comprehensive knowledge plus marketing, finance, management, which limits the space for business development, reducing the timeliness of entrepreneurship education.

\section{Classroom Teaching Organization is Conservative}

Undergraduate classroom traditional teaching methods are very conservative, failed to start the classroom team formation, is not conducive to student entrepreneurship team education. Although 
colleges and universities pay more and more attention to innovation and entrepreneurship education, many colleges and universities to open education in the form of general education class.

Some of them are simply in the form of form and are not reflected in the curriculum system of the student training program. The students' knowledge of innovation and entrepreneurship education is only at the level of elective selection. The university is based on the training program and completed according to the established curriculum system Teaching and Personnel training. Therefore, in order to achieve the perfect integration of innovative entrepreneurship education and professional teaching, it is definitely not to increase the number of courses, engage in several lectures can be, but should cultivate programs and curriculum in all aspects of innovation into the concept of entrepreneurship, innovation and entrepreneurship awareness, innovation and entrepreneurship knowledge and entrepreneurship career "three levels of training.

\section{Third, "Mentor + Project + Team" Entrepreneurial Education Model Analysis}

\section{Mode Interpretation}

"Instructor + team + project" business model is the students in the entrepreneurial guidance of teachers under the leadership of the project construction as a breakthrough, By the experience of entrepreneurship to achieve real business entrepreneurship education.

\section{Mode Connotation}

(1) To Build A "mentor + project + team" Integrity System

Whether the entrepreneurial system of colleges and universities can run scientifically, whether it can maintain the balance in entrepreneurial education and realize the sustainable development of entrepreneurship education. "Mentor + project + team" entrepreneurial model from a systematic perspective to perfect the emergence of college students operating mechanism of innovation and entrepreneurship. This model constitutes a complete system, the operation of the operation through the "material cycle, energy flow, information transmission" and other interactions to maintain the system of ecological balance operation, to achieve the sustainable development of student entrepreneurship education. In the course of practice, the model mainly through the following three mechanisms to maintain entrepreneurial students and the ecological factors between the information transmission, energy flow more effective.

(2) To Achieve the Integration of College Entrepreneurship Education Mechanism

"Instructor + project + team" in the specific practice requires instructors to teach and research depth of integration, through teaching to explore the perspective of research, through research to promote teaching. At the same time, the depth of integration of theory and practice, "mentor + project + team"

Entrepreneurial model more attention to the unity of entrepreneurship education, education process "more emphasis on entrepreneurial practice, the biggest bright spot is the project as the carrier, to achieve the practice of the theory, so that students in the 'real knife' experience in business, so Increase students' entrepreneurial experience and entrepreneurial knowledge.

(3) to Achieve the Open Mechanism of Entrepreneurship Education in Colleges and Universities

"Mentor + project + team" entrepreneurial education model in the mentor's choice, project innovation, team building and so on all reflect the open principle. The model breaks through the shackles of the traditional educational system of entrepreneurship, recruiting talent, playing the mentor to lead, pass, help, with advantages, pay attention to students creative innovation project incubation. Team building is the use of open mechanism, the team members of the professional, the ability to different, complement each other, can be cross-linked, cross-professional, cross-year students.

(4) to Achieve the Interaction Mechanism of Entrepreneurial Education in Colleges and Universities

"Mentor + project + team" entrepreneurial model than the other business education is the biggest difference between the interactive mechanism. In this model, the instructor interacts with the student, communicates the entrepreneurial information, hatch the entrepreneurial project; the student interacts with the student to discuss the landing practice of the entrepreneurial project; the team interacts with the team, learns from each other, encourages and equitably. 


\section{Mode Advantage}

(1) Focus on the Mentor Team Building

"Mentor + project + team" business model is very focused on the construction of the tutor team, mainly in three aspects: First, pay attention to the existing mentor training, focus on the accumulation of entrepreneurial education experience and scientific research ability to enhance. Such as inviting experts to guide each year, tutors learn from each other to learn, improve their own entrepreneurial education and scientific research capabilities. Second, focus on the expansion of mentor power. To absorb the strength of entrepreneurial tutor eclectic, talent, mentor team both teaching and research elite, and successful entrepreneurs outside the school concurrently entrepreneurial mentor. Third, pay attention to the development of the mentor evaluation. The evaluation of the mentor is more concerned with the teacher's guidance to the students' entrepreneurial projects, and strengthen the dynamic management of the instructors through the practical planning and guidance of the projectors.

(2) Focus on Entrepreneurial Projects as the Carrier

In addition to the entrepreneurial mentor to carry out specialized business guidance, the university should also have a specific entrepreneurial project as a carrier, so that students in the entrepreneurial practice to learn entrepreneurial skills, improve entrepreneurship. The impact of the project as a carrier on the whole college education system is mainly manifested in two aspects: First, change the traditional entrepreneurial education in paper practice, emphasizing entrepreneurial practice, so that students do secondary school, learn to do, through rational A venture project practice, and enhance the relevance of entrepreneurship education. Second is to achieve

The start of the project to achieve The start of the project to achieve the real business for students to lay the foundation.

(3) Interested in the Development of the Team Building

From the perspective of the construction of entrepreneurial team, the college pay more attention to the team's cooperative learning, interested in the development of team training. From the training point of view, with the traditional tutor system is the same emphasis on the mentor's guiding role, the difference is more emphasis on relying on the strength of the team to develop students' selffertility. Students learning motivation mainly comes from the team members need each other, this is conducive to students' active learning and growth, team training advantages highlighted. From the training content, covering the entrepreneurial development planning guidance, business incubation, entrepreneurial project development, entrepreneurial spirit and so on.

\section{Fourth, "Mentor + Project + Team" Entrepreneurial Education Model Implementation \\ Colleges and Universities to Provide a Good Start for the Education of Entrepreneurship Conditions}

Colleges and universities in the specific business education to take due responsibility. To this end, students should provide a policy environment to support the development of a comprehensive vocational education policy, focus on optimizing the policy environment of entrepreneurship education, through incentives to guide entrepreneurship initiative. Colleges and universities can also open a financial channel for entrepreneurship, all-round introduction of social resources to support vocational students entrepreneurship. Of course, colleges and universities should make full use of their own scientific research advantages, the formation of a dedicated research team for entrepreneurship education to provide intellectual support, integration of major entrepreneurial advantages of resources, combined with the actual practice of innovative business model, optimize innovation and entrepreneurship education, highlighting the effectiveness of education.

\section{Construction of Entrepreneurship Education Ecosystem in Higher Vocational Colleges}

First of all, from the impact of entrepreneurial education ecosystem external factors, colleges and universities should do a good job in service management, to facilitate entrepreneurship education, coordination of various functional departments for the school entrepreneurship education to provide intelligence, capital, resources and other support. At the same time, in terms of the internal factors of the entrepreneurial ecosystem, the university should first establish the entrepreneurial base of 
college students, set up the goal of entrepreneurship education, innovate the practice mode of entrepreneurship education, cultivate the main entrepreneurial factors and optimize the practice of entrepreneurship education.

\section{Focus on the Co-Cultivation of the Advantages of Major Entrepreneurship Education}

Not only for the cultivation of a single advantage of resources, but also to pay attention to the interaction between multiple resources on the whole entrepreneurial education system. Therefore, in the cultivation of entrepreneurship education system, one should pay attention to the training and management of entrepreneurship instructors, select the rich entrepreneurial education experience and scientific research strength as a teacher, while focusing on the mentor training and encouragement; the second is to focus on Entrepreneurship projects to cultivate the project as the carrier of entrepreneurial education more targeted, "learning with the combination of" entrepreneurial education training model highlights the effectiveness of education.

\section{Summary}

Nurturing entrepreneurial team. Nurturing entrepreneurial team can be interested in entrepreneurs together, we unite and cooperate to provide entrepreneurial wisdom, mutual learning, mutual encouragement, common progress and common development, through collective wisdom and ability to break through the difficulties of entrepreneurship, change individual entrepreneurship thin The situation, to work together to ensure the sustainable development of venture projects.

\section{Acknowledgements}

Jilin Province Education Science "13th Five-Year Plan" 2016 annual issues: local college students core competence and curriculum reform research; group entrepreneurial model used in Jilin Province, college entrepreneurship education research.

\section{References}

[1] $\mathrm{Xu}$ Ming, "Internet + " era of college students entrepreneurial model selection and path optimization [J] China Youth Social Sciences, 2015 (09)

[2] Badariah $\mathrm{Hj}$ Din; Abdul Rahim Anuar; Mariana Usman, The Effectiveness of the Entrepreneurship Education Program in Upgrading Entrepreneurial Skills among Public University Students [J] Proceda - Social and Behavioral Sciences, 2016 (06) 